\title{
An alternative approach to assess the habitat selection of Folsomia candida in contaminated soils
}

\author{
Jaume Bori $\cdot$ Maria Carme Riva \\ Center for Research and Innovation in Toxicology (CRIT-Innotex Center), Technical \\ University of Catalonia (UPC). Ctra. Nac. $150 \mathrm{Km}$ 15, 08227 Terrassa (Barcelona) \\ Spain.
}

Corresponding author: Jaume Bori Dols /+34 937398396 / jaume.bori@crit.upc.edu

\begin{abstract}
Avoidance tests with collembolans provide a quick assessment of soil quality. However, some parameters of the procedure can be modified in order to increase its performance. In this study we assessed the tendency of Folsomia candida to avoid soils contaminated with boric acid (350-700-1400-2800-5600 mg/kg soil dry weight (dw)), phenmedipham (35-70-140-280 $\mathrm{mg} / \mathrm{kg} \mathrm{dw}$ ) or petroleum hydrocarbons (1312-1838-2625-3675-5250 $\mathrm{mg} / \mathrm{kg} \mathrm{dw}$ ) by preferring an untreated soil. Two separate methodologies were applied, the one presented in the ISO standard 17512:2 and a modified version of the Petri dish method that allowed data acquisition after 2, 24 and 48 hours of exposure. After combining data from three separate trials, effective median concentration values $\left(\mathrm{EC}_{50}\right)$ from the presented method were lower and showed similar or less variability than those from the ISO procedure, suggesting the modified protocol as a suitable alternative screening tool.
\end{abstract}

Keywords: Avoidance, screening, Collembola, soil contamination

\section{Introduction}

Ecotoxicological bioassays became an essential tool for the assessment of risks associated with soil contaminants (Loureiro et al. 2005). In this context, some laboratory ecotoxicological tests follow standardized guidelines to study the effects that soil contaminants cause to a well defined set of non-target model organisms. Also for collembolans, which contribute to the fertility of soils through decomposition and nutrient cycling processes (Culik and Zeppelini 2003), standardized test guidelines have been developed assessing their potential avoidance behavior of a contaminated soil by preferring a control soil as habitat (ISO standard 17512:2 (ISO 2011)). This procedure provides information comparable to the one obtained with other more complex ecotoxicological soil tests but requires less experimental efforts (Domene et al. 2011).

The suitability of the standard avoidance test with Collembola as screening tool of soil contamination relies on its ecological relevance and its sensitivity, while it also benefits from exposure times shorter than in acute or reproduction tests and can therefore be routinely applied in 'on site' procedures (Eisenträger et al. 2005). Despite those benefits, avoidance tests present a high variability in their results, which is at least partly explained by the gregarious behavior of collembolans and unexplained shifts in the cultures avoidance responses over time (Filser et al. 2013). According to Filser et al. (2000), the aggregation of individuals in the test containers can be controlled by reducing their density (for instance performing single specimen tests). Regarding 
temporal variations, Filser and Hölscher (1997) suggested involving sufficient replication and assessing the behavior regularly during the bioassay. Additionally, Van Gestel (2012) highlighted the need to review existing test guidelines in order to make them applicable to new chemicals. Such revision should involve the miniaturization of test systems since many new materials can only be produced in small amounts.

In this study we present an alternative approach that aims to strengthen the use of avoidance tests with Collembola as early-warning tool of soil contamination through the simplification of the test preparation and data collection. Current avoidance tests with collembolans allow test organisms to dig into soils. Consequently, a destructive and time-consuming analysis of soil samples by flooding and counting the floating individuals is required. Similarly to the study by Aldaya et al. (2006), the presented alternative procedure uses $55 \mathrm{~mm}$ Petri dishes, requires fewer resources and involves a slight compression of the soils to prevent collembolans from hiding, thus allowing the observation of test organisms through the transparent lid of the vessel. The major purpose of this work is to study whether the presented procedure can provide information equivalent to the one obtained following the ISO standard 17512:2. Additionally, we aimed at assessing whether a reduction in exposure times can be realized while still ensuring reliable data. To attain these goals, several tests following the ISO standard and the Petri dish procedure were performed. Data from the ISO standard was collected after 48 hours of exposure whereas exposure times with the Petri dish procedure were 2, 24 and 48 hours. Manifold concentrations of the two reference chemicals recommended by the ISO standard 17512:2 (boric acid and phenmedipham) as well as a soil contaminated with petroleum hydrocarbons sampled from the field were selected as test items.

\section{Materials and methods}

Collembolans from the species Folsomia candida (Isotomidae) were obtained from synchronized cultures maintained at the Center for Research and Innovation in Toxicology of the Technical University of Catalonia (Spain). Animals were cultured at $20 \pm 2^{\circ} \mathrm{C}$ in $145 / 20 \mathrm{~mm}$ Petri dishes filled with a substrate of plaster of Paris and charcoal $(8: 1, \mathrm{w} / \mathrm{w})$ to a height of approximately $10 \mathrm{~mm}$. Individuals were fed twice a week with granulated dry yeast added in small amounts (approximately $2 \mathrm{mg}$ of yeast per organism and week) to avoid spoilage by fungi. Adult organisms (12-20 days old) were selected for avoidance tests.

A soil from a known natural uncontaminated area near the laboratory (Pereira Miranda et al. 2011) was selected as control soil. Samples from the topsoil $(0-20 \mathrm{~cm}$ depth) were air-dried and sieved through a $2 \mathrm{~mm}$ mesh. Several soil parameters were analyzed: texture (Pipette method), $\mathrm{pH}$ (KCl, $1 \mathrm{~mol} / \mathrm{L}$ )(ISO 2005a), Water Holding Capacity (WHC)(ISO 2011), organic matter (Walkley and Black 1934), moisture (ISO 1993), and cation exchange capacity (CEC)(Schollenberger and Simon 1945)(Table 1).

In this study, avoidance tests with collembolans were carried out following two different experimental procedures: a) using the ISO standard protocol (ISO 2011) and b) using $55 \mathrm{~mm}$ Petri dishes as test containers. The selected exposure times were 48 hours with the ISO procedure and 2, 24 and 48 hours for the Petri dish methodology. Median effective concentration $\left(\mathrm{EC}_{50}\right)$ values were determined 3 times for each test substance and exposure time in independent experimental runs. Five replicates per test concentration were prepared. Additionally, dual-control tests (10 replicates) with control soil at both sides of the test container were performed with each experimental 
run in order to validate the tests by checking the homogeneity in the distribution of collembolans. Tests were performed in an environmental chamber at $20 \pm 2{ }^{\circ} \mathrm{C}$ under a 16:8 h light:dark cycle.

Table 1. Physical-chemical characteristics of the control and field soils.

\begin{tabular}{cccccccc}
\hline & Texture & $\mathrm{pH}_{\mathrm{KCl}}$ & WHC (\%) & Organic matter (\%) & Moisture (\%) & $\begin{array}{c}\text { CEC } \\
(\mathrm{meq} / 100 \mathrm{~g})\end{array}$ & $\begin{array}{c}\text { Petroleum hydrocarbons } \\
(\mathrm{C} 10-\mathrm{C} 40) \\
(\mathrm{mg} / \mathrm{kg})\end{array}$ \\
\hline Control Soil & Clay loam & 7.6 & 41.4 & 10.7 & 18.6 & 22.8 & - \\
Field soil & Silty loam & 7.9 & 24.9 & 8.3 & 7.5 & 23.4 & 5250
\end{tabular}

The control soil was spiked with the reference chemicals boric acid (Scharlab, 99.8\% pure) and phenmedipham (Sigma-Aldrich, 99.7\% pure)(ISO 2011). A stock solution of each substance was prepared with the proper solvent (deionized water for boric acid and methanol (Labkem, 99.5\% pure) for phenmedipham). Spiking solutions providing the desired concentration of test substance in soil and a moisture content between 40 and $60 \%$ of the Water Holding Capacity of the soil were obtained by diluting the stock

solutions. Batches of control soil were homogeneously contaminated with the corresponding solution and divided into two sub-batches (one for the application of each methodology). The control soil was treated with five concentrations of boric acid corresponding to 350.0, 700.0, 1400.0, 2800.0 and $5600.0 \mathrm{mg} / \mathrm{kg}$ dry soil and was left for equilibration before starting the tests. In the case of phenmedipham, the control soil was spiked with the corresponding solution, thoroughly mixed and left overnight until methanol was evaporated. Final concentrations of phenmedipham in soils were 35.0, 70.0, 140.0 and $280.0 \mathrm{mg} / \mathrm{kg}$ soil dry weight (dw). Additionally, a soil from a site (hereinafter field soil) contaminated with petroleum hydrocarbons was selected to ensure the transferability of the proposed test design to a more realistic scenario. Sampling and pre-treatment of the field soil were carried out as described for the control soil. Physical-chemical properties of the field soil can be seen in Table 1 . Hydrocarbons in soil (C10-C40) were determined through gas chromatography and flame ionization detector (GC-FID)(Table 1). Final test concentrations were 25, 35, 50, 70 and100\% of field soil mixed with control soil, corresponding to 1312, 1838, 2625, 3675 and 5250 mg of petroleum hydrocarbons per $\mathrm{kg}(\mathrm{dw})$. When dilution of the field soil was needed, it was achieved by mixing it with the control soil (w/w). Prior to the start of the tests, soils were hydrated with deionized water until the desired moisture content was reached.

According to the procedure described in the ISO standard 17512:2 (ISO 2011), cylindrical plastic containers (diameter $8 \mathrm{~cm}$; depth $8 \mathrm{~cm}$ ) were divided into two equal sections. Approximately $30 \mathrm{~g}$ (wet weight) of control and contaminated soils were placed into the corresponding section and the divider was removed. Twenty organisms were carefully placed on top of the soils. After 48 hours of exposure, the two soils were separated and the soil from each section was carefully emptied. Each subsample was flooded with water and after gentle stirring the animals floating on the water surface were counted. Missing individuals were considered as dead and discarded for the subsequent calculations. The alternative method used plastic Petri dishes $(55 \mathrm{~mm}$ diameter, $14 \mathrm{~mm}$ height) as test vessels. Petri dishes were divided into two sections filled with $6 \mathrm{~g}$ (wet weight) of the corresponding soil. Wet soils were pressed by hand in order to obtain a suitable texture that prevented collembolans from hiding into soil. Ten collembolans were carefully placed on top of the line dividing the two sections. The distribution of individuals was recorded after 2, 24 and 48 hours of incubation. 
Data from dual-control tests were analyzed using the two-tailed Fisher Exact test (Zar 1998) to check the homogeneous distribution of the organisms. Following the recommendations of the ISO 17512:2 standard (ISO 2011), the percentage of avoidance in the avoidance tests was calculated in each replicate by the equation $x=\left[\left(n_{\mathrm{c}}-n_{\mathrm{t}}\right) / N\right] \quad \mathrm{X}$ 100 , where $x=$ percent avoidance, $n_{\mathrm{c}}=$ number of individuals in the control soil, $n_{\mathrm{t}}=$ number of individuals in the test soil, and $N=$ total number of individuals. Negative avoidance values (lack of avoidance) were transformed to zero. The avoidance median effective concentration values $\left(\mathrm{EC}_{50}\right)$ and their $95 \%$ confidence limits were calculated by Probit regression with maximum likelihood estimation. A normal or logistic distribution was assumed depending on the results from the Kolomogorov-Smirnov normality test. $\mathrm{EC}_{50}$ values were compared between experimental procedures and exposure times within the same procedure using the confidence interval ratio test recommended by Wheeler et al. (2006). Statistical analysis was performed using SPSS software (SPSS 15.0 for Windows; SPSS Inc., Chicago, IL, USA) and Minitab Statistical Software (Minitab 15.0; Minitab Inc., State College, PA, USA).

\section{Results and Discussion}

Dual-control tests with both methodologies showed an even distribution of collembolans, with a number of organisms per section between 40 and $60 \%$ of the total. Additionally, the number of dead or missing organisms never reached values higher than 20\% per treatment, thus meeting the requirements of the ISO standard (ISO, 2011)(Table 2). Results from avoidance tests revealed the high variability inherent in the procedures, with estimated $\mathrm{EC}_{50}$ values that markedly varied with the trial within each test substance and experimental procedure. In some cases effective median concentration values could not be reported. In order to improve the results of the avoidance tests, data from the three available trials were combined. To do so, the mean avoidance percentage of all replicates per treatment $(\mathrm{N}=15)$ was used for the calculation of the probit regressions. After combining the results, $\mathrm{EC}_{50}$ values were successfully calculated for both experimental procedures (Table 2).

Table 2. $\mathrm{EC}_{50}$ avoidance values, confidence limits and percentage of mortality per replicate (mean $\pm \mathrm{SD}$ ) estimated with the data combined from the available trials ( $N=15$ replicates per treatment). $\mathrm{EC}_{50}$ values within the same test substance followed by the same letter are not significantly different $(P>0.05)$. Pd: Petri dish

\begin{tabular}{clccccc}
\hline Test substance & Procedure & $X^{2}$ & $P$ & EC $_{50}$ & Confidence limits (95\%) & Mortality (\%) \\
\hline & ISO 48h & 3.45 & 0.179 & 3397.58a & $2521.10-4578.68$ & $4.8 \pm 1.9$ \\
Boric acid & Pd. 2h & 1.30 & 0.730 & $1124.63 \mathrm{~b}$ & $893.26-1415.92$ & $0.5 \pm 0.9$ \\
$(\mathrm{mg} / \mathrm{kg})$ & Pd. 24h & 1.04 & 0.792 & $1034.24 \mathrm{~b}$ & $836.78-1290.21$ & $1.3 \pm 1.6$ \\
& Pd. 48h & 4.51 & 0.105 & $1729.90 \mathrm{~b}$ & $1017.15-2692.90$ & $2.3 \pm 2$ \\
\hline & ISO 48h & 4.67 & 0.097 & $289.76 \mathrm{a}$ & $225.14-372.92$ & $7.9 \pm 4.3$ \\
Phenmedipham & Pd. 2h & 5.08 & 0.079 & $127.93 \mathrm{~b}$ & $97.51-167.85$ & $1.7 \pm 0.7$ \\
(mg/kg) & Pd. 24h & 2.79 & 0.248 & $155.14 \mathrm{ab}$ & $83.28-289$ & $4.3 \pm 2.2$ \\
& Pd. 48h & 1.25 & 0.263 & $201.49 \mathrm{ab}$ & $121.31-334.66$ & $7.3 \pm 4.1$ \\
\hline Petroleum & ISO 48h & 0.42 & 0.810 & $2744.70 \mathrm{a}$ & $2276.93-3308.55$ & $11 \pm 1.8$ \\
hydrocarbons & Pd. 2h & 1.45 & 0.485 & $1392.30 \mathrm{~b}$ & $1195.43-1621.73$ & $1.9 \pm 2$ \\
(mg/kg) & Pd. 24h & 3.08 & 0.214 & $1487.85 \mathrm{~b}$ & $1326.15-1669.50$ & $2.5 \pm 1.6$ \\
& Pd. 48h & 5.44 & 0.066 & $1615.95 \mathrm{~b}$ & $1463.70-1780-43$ & $4 \pm 1.6$ \\
\hline
\end{tabular}

Effective median concentration values estimated after the exposure to the reference 
substances boric acid and phenmedipham were in some cases higher than those found in literature. For boric acid, previous studies reported $\mathrm{EC}_{50}$ of $1440 \mathrm{mg} / \mathrm{kg}$ (Becker et al. 2011) after applying the ISO standard 17512:2 in OECD artificial soil and questioned the suitability of boric acid as reference substance in avoidance tests with collembolans due to the low sensitivity of the organisms (Amorim et al. 2012). Our results agreed with those studies, reporting an $\mathrm{EC}_{50}$ value for the ISO test of $3397.58 \mathrm{mg} / \mathrm{kg}$ (Table 2). Differences in the $\mathrm{EC}_{50}$ values between studies can be explained by the soil typology since the percentage of organic matter and clay, soil constituents related with the binding of boron (Goldberg 1997), were higher in our soil (10.7 and 29.1\% respectively) than in the OECD artificial soil (approximately 8 and 20\% respectively). Regarding the exposure to phenmedipham, $\mathrm{EC}_{50}$ values from both methodologies presented in this study were two orders of magnitude higher than those calculated by Diogo et al. (2007)(4.14-8.01 mg phenmedipham/kg) after applying Betosip ${ }^{\circledR}$ (active ingredient phenmedipham) to OECD artificial soil following the ISO standard. In this case, differences in the results between studies were attributed to soil typology and to the form in which the test substance was applied. The contents of organic matter and silt, soil constituents known to reduce the bioavailability of phenmedipham (Domene et al. 2012), were again higher in our soil (32,4\% of silt) than in the OECD artificial soil (approximately $10 \%$ silt content). More importantly, since the ISO standard 17512:2 only requires a reference substance that has phenmedipham as the unique active ingredient, several products that fulfill this requirement are usually applied. While we used pure phenmedipham as test substance, the study by Diogo et al. (2012) applied the commercial formulation Betosip ${ }^{\circledR}$, complicating the comparison of results due to the presence of co-formulants with unknown effect on the test organisms. No previous studies were found where avoidance $\mathrm{EC}_{50}$ values were estimated after exposing collembolans to pure phenmedipham. Nonetheless, results from the present study suggest that the pure compound is not the best choice as reference substance due to the low sensitivity shown by collembolans. Regarding the exposures to petroleum hydrocarbons, the detected avoidance responses were similar to those documented by Hentati et al. (2013) and Aldaya et al. (2006) after assessing hydrocarbon-contaminated field soils with the ISO standard and a procedure involving Petri dishes respectively, thus confirming the sensitivity of the test organisms towards the presence of hydrocarbons. For all tested substances, results from the Petri dish procedure presented similar or lower variability and $\mathrm{EC}_{50}$ values (i.e higher sensitivity) than the ISO method. In the exposure to boric acid and the hydrocarbon-contaminated field soil, $\mathrm{EC}_{50}$ estimates from the Petri dish procedure after all exposure times were significantly lower than those from the ISO methodology (Table 2). In the case of phenmedipham, a statistically lower $\mathrm{EC}_{50}$ value was only found after two hours of exposure due to the higher variability observed at longer exposure times. The higher sensitivity of avoidance tests with collembolans performed in Petri dishes was also reported by Boiteau et al. (2011) after applying modified versions of the plastic cup test (ISO 2005b) and of the Petri dish avoidance test (Aldaya et al. 2006) in the assessment of the avoidance response of $F$. candida to copper. No clear explanation for the higher sensitivity of the Petri dish procedure was found although we hypothesized that it might be related to the disposal of soil in the test chambers. Due to the much lower volume of soil available for test organisms in the Petri dishes, they had fewer chances to find a suitable spot in the contaminated section and therefore they migrate more likely to the non-contaminated soil .

The application of the Petri dish procedure allowed the observation of temporal trends 
in the avoidance responses. $\mathrm{EC}_{50}$ values for all tested substances tended to increase (i.e lower sensitivity) throughout time although no statistically significant differences were found between exposure times. Therefore, for the tested substances, an exposure of 2 hours may be sufficient when an early screening of soil contamination is required. A shortening of the exposure time was already suggested by Da-Luz et al. (2008) after finding consistent avoidance responses after 24 hours. Aldaya et al. (2006) and Lors et al. (2006) also established shorter exposure times of 20 to 100 minutes in their avoidance tests with collembolans. Even so, caution must be taken since the absence of significant differences between exposure times might be explained by the high variability of the results, especially in the case of phenmedipham.

Findings of our study suggest that the presented procedure could become a valuable tool for an initial screening of soil contamination supplying rapid information for future decision-taking. Despite the suboptimal sensitivity of the test organisms to some of the tested substances, the Petri dish method provided information equivalent or even more sensitive than the ISO standard and represented an improvement in terms of time and resources needed for the performance of the test. Additionally, data recorded in this study pointed out that an exposure time of two hours with the Petri dish avoidance test may be enough for an early warning tool. Despite the potential benefits of the presented test, further research is required in order to reduce the high variation of results inherent in avoidance tests. At the same time, the performance of the test and the reduction of the exposure time from 48 to 2 hours should be validated with other soils and chemical substances. Finally, a revision of the reference substances is suggested due to the low sensitivity of $F$. candida to boric acid and pure phenmedipham.

\section{Acknowledgments}

The authors thank Dr. Juan Ribó for his support in the performance of the study. This research was funded by Universitat Politècnica de Catalunya (UPC) and R\&D Gestió i Serveis Ambientals S.L. (Spain) through a doctoral grant to Jaume Bori (Beca UPC Recerca 2012) and by the Spanish Ministry of Economy and Competitiveness through the project SOILBIOMONITOR (CTM2010-18167).

\section{Compliance with ethical standards}

The authors declare that they have no conflict of interest.

\section{References}

Aldaya MM, Lors C, Salmon S, Ponge JF (2006) Avoidance bio-assays may help to test the ecological significance of soil pollution. Environ Pollut 140: 173-180.

Amorim MJB, Natal-da-Luz T, Sousa JP, Loureiro S, Becker L, Römbke J, Soares AMVM (2012) Boric acid as reference substance: pros, cons and standardization. Ecotoxicology 21: 919-924.

Becker L, Scheffczyk A, Förster B, Oehlmann J, Princz J, Römbke J, Moser T (2011) Effects of boric acid on various microbes, plants, and soil invertebrates. J Soils Sediments 11: 238-248.

Boiteau G, Lynch DH, MacKinley P (2011) Avoidance tests with Folsomia candida for the assessment of copper contamination in agricultural soils. Environ Pollut 159: 903-906. 
Culik MP \& Zeppelini D (2003) Diversity and distribution of Collembola (Arthropoda: Hexapoda) of Brazil. Biodivers Conserv 12: 1119-1143.

Da-Luz TN, Amorim MJB, Römbke J, Sousa JP (2008) Avoidance tests with earthworms and springtails: Defining the minimum exposure time to observe a significant response. Ecotoxicol Environ Saf 71: 545-551.

Diogo JB, da-Luz TN, Sousa JP, Vogt C, Nowak C (2007) Tolerance of Genetically Characterized Folsomia candida Strains to Phenmedipham Exposure. J Soils Sediments 7: 388-392.

Domene X, Chelinho S, Campana P, Natal-da-Luz T, Alcañiz JM, Andrés P, Römbke J, Sousa P (2011) Influence of soil properties on the performance of Folsomia candida: implications for its use in soil ecotoxicology testing. Environ Toxicol Chem vol. 30 no. 7: 1497-1505.

Domene X, Chelinho S, Campana P, Alcañiz JM, Römbke J, Sousa JP (2012) Applying a GLM-based approach to model the influence of soil properties on the toxicity of phenmedipham to Folsomia candida. J Soils Sediments 12: 888-899.

Eisenträger A, Hund-Rinke K, Neumann-Hensel H, Weber G, Jaensch S, Römbke J (2005) Routine use of ecotoxicological tests for the assessment of contaminated soils. In: 9th International FZK/TNO Conference on Soil and Water Systems. Proc. Consoil. Bordeaux, France.

Filser J \& Hölscher G (1997) Experimental studies on the reactions of Collembola to copper contamination. Pedobiologia 41: 173-178.

Filser J, Wittmann R, Lang A (2000) Response types in Collembola towards copper in the microenvironment. Environ Pollut 107: 71-78.

Filser J, Wiegmann S, Schröder B (2013) Collembola in ecotoxicology: Any news or just boring routine? Appl Soil Ecol 83: 193-199.

Goldberg S (1997) Reaction of boron with soils. Plant Soil 193: 35-48.

Hentati O, Lachhab R, Ayadi M, Ksibi M (2013) Toxicity assessment for petroleumcontaminated soil using terrestrial invertebrates and plant bioassays. Environ Monit Assess 185: 2989-2998.

International Organization for Standardization (1993) Soil quality - Determination of dry matter and water content on a mass basis - Gravimetric method. International Organization for Standardization, No. 11465. Geneva, Switzerland.

International Organization for Standardization (2005a): Soil quality - Determination of pH. International Organization for Standardization, No. 10390. Geneva, Switzerland.

International Organization for Standardization (2005b) Soil quality - avoidance test for testing the quality of soils and the toxicity of chemicals - test with earthworms (Eisenia fetida). ISO 17512 (Draft), Geneva, Switzerland.

International Organization for Standardization (2011): Soil quality - Avoidance test for determining the quality of soils and effects of chemicals on behavior - Test with collembolans (Folsomia candida). International Organization for Standardization, No. 17512-2. Geneva, Switzerland.

Lors C, Aldaya MM, Salmon S, Ponge JF (2006) Use of avoidance test for the assessment of microbial degradation of PAHs. Soil Biol Biochem 38: 21992204.

Loureiro S, Soares AMVM, Nogueira AJA (2005) Terrestrial avoidance behaviour tests as screening tool to assess soil contamination. Environ Pollut 138: 121-131.

Pereira Miranda AF, Rodrigues JML, Barata C, Riva C, Nugegoda D, Soares AMVM (2011) The use of Daphnia magna immobilization tests and soil microcosms to evaluate the toxicity of dredged sediments. J Soils Sediments 11: 373-381. 
Schollenberger CJ \& Simon RH (1945) Determination of exchange capacity and exchangeable bases in soil-ammonium acetate method. Soil Sci 59: 13-24.

Van Gestel CAM (2012) Soil ecotoxicology: state of the art and future directions. Zoo Keys 176: 275-296.

Walkley A \& Black JA (1934) An examination of the Degtjareff method for determining soil organic matter and a proposed modification of the chromic acid titration method. Soil Science 37: 29-38.

Wheeler MW, Park RM, Bailer AJ (2006) Comparing median lethal concentration values using confidence interval overlap or ratio tests. Environ Toxicol Chem vol. 25 no. 5: 1441-1444.

Zar JH (1998): Biostatistical analysis, $5^{\text {th }}$ Edition. Prentice-Hall, Upper Saddle River, NJ, USA, pp 561-569. 